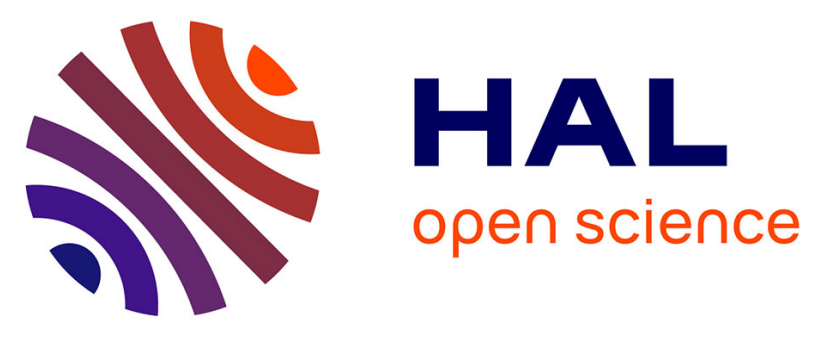

\title{
The 2013 Ibiza Calibration Campaign of Jason-2 and SARAL Altimeters
}

Frédéric Frappart, Nicolas Roussel, Richard Biancale, Juan José Martinez Benjamín, Florian Mercier, Félix Perosanz, Jorge Garate Pasquin, José Martín Davila, Begoña Perez Gomez, Carlos Gracia Gomez, et al.

\section{To cite this version:}

Frédéric Frappart, Nicolas Roussel, Richard Biancale, Juan José Martinez Benjamín, Florian Mercier, et al.. The 2013 Ibiza Calibration Campaign of Jason-2 and SARAL Altimeters. Marine Geodesy, 2015, 38 (1), pp.219-232. 10.1080/01490419.2015.1008711 . hal-01364274

\section{HAL Id: hal-01364274 \\ https://hal.science/hal-01364274}

Submitted on 25 Jan 2022

HAL is a multi-disciplinary open access archive for the deposit and dissemination of scientific research documents, whether they are published or not. The documents may come from teaching and research institutions in France or abroad, or from public or private research centers.
L'archive ouverte pluridisciplinaire HAL, est destinée au dépôt et à la diffusion de documents scientifiques de niveau recherche, publiés ou non, émanant des établissements d'enseignement et de recherche français ou étrangers, des laboratoires publics ou privés.

\section{(ㅇ)(1) $\$$}

Distributed under a Creative Commons Attribution - NonCommerciall 4.0 International 


\title{
The 2013 Ibiza Calibration Campaign of Jason-2 and SARAL Altimeters
}

\author{
F. FRAPPART, ${ }^{1,2,3}$ N. ROUSSEL, ${ }^{1,3}$ R. BIANCALE, ${ }^{1,3,4}$ \\ J. J. MARTINEZ BENJAMIN,$^{5}$ F. MERCIER, ${ }^{1,3,4}$ \\ F. PEROSANZ, ${ }^{1,3,4}$ J. GARATE PASQUIN,${ }^{6}$ J. MARTIN \\ DAVILA, ${ }^{6}$ B. PEREZ GOMEZ, ${ }^{7}$ C. GRACIA GOMEZ, ${ }^{5}$ \\ R. LOPEZ BRAVO, ${ }^{5}$ A. TAPIA GOMEZ, ${ }^{5}$ J. GILI RIPOLL, ${ }^{5}$ \\ M. HERNANDEZ PAJARES, ${ }^{5}$ M. SALAZAR LINO, ${ }^{8}$ \\ P. BONNEFOND, ${ }^{9}$ AND I. VALLES CASANOVA ${ }^{5}$ \\ ${ }^{1}$ Géosciences Environnement Toulouse (GET) UMR5563, CNRS/IRD/UPS, \\ OMP, Toulouse, France \\ ${ }^{2}$ Laboratoire d'Etudes en Géophysique et Océanographie Spatiales (LEGOS) \\ UMR5566, CNES/CNRS/IRD/UPS, OMP, Toulouse, France \\ ${ }^{3}$ Groupe de Recherche en Géodésie Spatiale, Toulouse, France \\ ${ }^{4}$ Centre National d'Etudes Spatiales (CNES), Toulouse, France \\ ${ }^{5}$ Department Geotechnical Engineering and Geosciences, Technical University \\ of Catalonia (UPC), Barcelona, Spain \\ ${ }^{6}$ Real Instituto y Observatorio de la Armada (ROA), San Fernando, Cadiz, Spain \\ ${ }^{7}$ Puertos del Estado (PE), Madrid, Spain \\ ${ }^{8}$ Universidade do Porto, Porto, Portugal \\ ${ }^{9}$ Géoazur, CNRS/IRD/UNS, OCA, Valbonne, France
}

\begin{abstract}
This study presents the results of the 2013 Ibiza (Western Mediterranean) calibration campaign of Jason-2 and SARAL altimeters. It took place from 14 to 16 September 2013 and comprised two phases: the calibration of the GNSS (Global Navigation Satellite System) buoys to estimate the antenna height of each of them and the absolute calibration to estimate the altimeter bias (i.e., the difference of sea level measured by radar altimetry and GNSS). The first one was achieved in the Ibiza harbor at a close vicinity of the Ibiza tide gauge and the second one was performed at » $40 \mathrm{~km}$ at the northwest of Ibiza Island at a crossover point of Jason-2 and SARAL nominal groundtracks. Five buoys were used to delineate the crossover region and their measurements interpolated at the exact location of each overflight. The overflights occurred two consecutive days: 15 and 16 September 2013 for Jason-2 and SARAL, respectively. The GNSS data were processed using precise point positioning technique. The biases found are of $(; 0.1 \S 0.9)$ and $(; 3.1 \S 1.5) \mathrm{cm}$ for Jason-2 and SARAL, respectively.
\end{abstract}

Keywords satellite altimetry, calibration, GNSS buoys, tide gauge

Address correspondence to Frédéric Frappart, Observatoire Midi-Pyrénées, 14 Avenue Edouard Belin, Toulouse, 31400, France. E-mail: frederic.frappart@get.obs-mip.fr. 


\section{Introduction}

Accurate monitoring of sea-level variations using satellite altimetry requires a precise determination of the error budget of the altimeter measurements. Calibration of the altimetry missions is crucial for estimating sea surface height ( $\mathrm{SSH}$ ) bias and assessing the error balance of the altimetry measurement system. Besides, it is necessary for combining both spatially and temporally sea surface height ( $\mathrm{SSH}$ ) from different altimeters. The absolute calibration of the altimeter missions is used to compare the altimetry-derived SSH with independent measurements and consists in determining the bias between the SSH measured by an altimeter and an external ground truth (e.g., Cancet et al. 2013). Global Positioning System (GPS) receiver on buoys were early used for precise sea level estimates (Rocken et al. 1990) and calibration of Topex/Poseidon altimeter measurements (Born et al. 1994). Local absolute calibrations are performed under the altimeter groundtrack using tide gauge records or GNSS measurements either during a dedicated campaign (e.g., Bonnefond et al. 2003; Martinez Benjamin et al. 2004 in the Mediterranean Sea) or at permanent calibration facilities or Calibration/Validation (Cal/Val) sites in Corsica, Western Mediterranean Sea (e.g., Bonnefond et al. 2013) at Harvest platform, Eastern Pacific Ocean (e.g., Haines et al. 2010) in Gavdos, Eastern Mediterranean Sea (e.g., Mertikas et al. 2010), and Bass Strait, between Australia and Tasmania (e.g., Watson et al. 2011).

An altimetry calibration campaign was achieved in the Mediterranean Sea, close to the Ibiza Island (Baleares) area, September 2013 in the framework of a Spanish/French cooperation. Its goal was to estimate the absolute bias of AltiKa onboard SARAL, the first altimeter to operate in Ka band, through comparisons with GNSS measurements on buoys, and to compare it to Jason-2 absolute bias at a crossover of their respective groundtracks. A similar Spanish/French experiment was already performed for Jason-1 in June 2003 in this geographical area under the name IBIZA 2003 campaign (MartinezBenjamin et al. 2004).

A direct absolute altimeter calibration estimating the Jason-2 and SARAL biases was performed from direct overflights using GNSS buoys. This method does not require any modeling of geoid and tidal error (Bonnefond et al. 2013; Cancet et al. 2013). The crossover point between Jason-2 and SARAL North of Ibiza (around $40 \mathrm{~nm}$ ) and West of Mallorca island was found to be optimal for our purposes since it allows measurements at a one-day time-lag and a similar configuration of buoys for each satellite pass (Figure 1). Five buoys were deployed near a Jason-2/SARAL crossover point to determine the sea surface in the along-track and cross-track directions, to estimate by interpolation the SSH at the exact nadir point of the satellite. Here, we present the experimental settings of the campaign and the datasets used in this study, the methods used for comparing altimetry data with GNSS measurements, and the results of the absolute calibration.

\section{Datasets}

\section{Altimetry Data}

Jason-2. Jason-2 mission was launched on 20 June 2008 as a cooperative effort among CNES, EUMETSAT, NASA and NOAA. Its payload is mostly composed of the Poseidon-3 radar altimeter from CNES, the Advanced Microwave Radiometer (AMR) from JPL/NASA, and a triple system for precise orbit determination: the real-time tracking system DIODE of DORIS instrument from CNES, a GNSS receiver and a Laser Retroflector 
Array (LRA) from NASA. Jason-2 orbits at an altitude of $1336 \mathrm{~km}$, with an inclination of $66^{\circ}$, on a 10-day repeat cycle, providing observations of the Earth surface (ocean and land) from $66^{\circ}$ latitude North to $66^{\circ}$ latitude South. This orbit was formerly used by Topex/Poseidon, Jason-1 and 2, with an equatorial ground-track spacing of about $315 \mathrm{~km}$. Poseidon-3 radar altimeter is a two-frequency solid-state altimeter that measures accurately the distance between the satellite and the surface (range) and provides ionospheric corrections over the ocean. It operates at $\mathrm{Ku}(13.575 \mathrm{GHz})$ and $\mathrm{C}(5.3 \mathrm{GHz})$ bands. Its accuracy is expected to be about $2 \mathrm{~cm}$ over ocean. Raw data are processed by SSALTO (Segment Sol multimissions d'ALTimétrie, d'Orbitographie).

SARAL. SARAL mission was launched on 25 February 2013 as a joint effort of CNES and ISRO. Its payload comprised the AltiKa radar altimeter and bi-frequency radiometer, and a triple system for precise orbit determination: the real-time tracking system DIODE of DORIS instrument, a Laser Retroflector Array (LRA), and the Advanced Research and Global Observation Satellite (ARGOS-3). SARAL orbits at an altitude of $790 \mathrm{~km}$, with an inclination of $98.54^{\circ}$, on a 35-day repeat cycle, providing observations of the Earth surface (ocean and land) from $82.4^{\circ}$ latitude North to $82.4^{\circ}$ latitude South. This orbit was formerly used by ERS-1 \& 2 and ENVISAT, with an equatorial groundtrack spacing of about $85 \mathrm{~km}$. AltiKa radar altimeter is a solid-state mono-frequency altimeter that provides accurate range measurements. It is the first altimeter to operate at Ka-band $(35.75 \mathrm{GHz})$. Its accuracy is expected to be about $1 \mathrm{~cm}$ over ocean. More details about the AltiKa-SARAL mission can be found in (Verron et al. 2015).

The data used in this study come from the Geophysical Data Records (GDRs) for Jason-2 (GDR D) and SARAL (GDR T patch 2) and are made available by Centre de Topographie de l'Océan et de l'Hydrosphère (CTOH, http://ctoh.legos.obs-mip.fr/). Ranges are available every $20 \mathrm{~Hz}$ for Jason-2 and $40 \mathrm{~Hz}$ for SARAL. It corresponds to a measurement every 350 and $165 \mathrm{~m}$, respectively, along the track. Range values suitable to derive SSH are retracked using MLE4 (Amarouche et al. 2004) and MLE3 (Rodriguez 1988) algorithms, Maximum Likelihood Estimator with 4(3) degrees of freedom, applied to the Brown model (Brown 1977). They are provided in the GDRs for both Jason-2 and SARAL for the first one, and only Jason-2 for the second one. The type of the corrections applied to the altimetry data for comparison with GNSS data is summarized in Table 1. As the environmental corrections affect both altimetry and GNSS data, they were not applied.

\section{GNSS Data}

Five GNSS stations were installed on buoys (denominated on Figure 2c GRGS, LEGOS/ INSU, IPGP, UPC $1 \&$ 2). They are composed of three receivers TOPCON GB-1000

Table 1

Corrections applied to the altimetry data for each altimetry mission

Geophysical corrections

Altimetry

mission ionosphere dry troposphere wet troposphere sea state bias

Jason-2 bi-frequency (C-Ku) ECMWF-derived radiometer-derived empirical models

SARAL GIM-derived ECMWF-derived radiometer-derived empirical models 
with TOPCON PG_A1+GP antennas and two receivers and antennas TOPCON HIPER.

All of them were acquiring data at a sample rate of $1 \mathrm{~Hz}$.

\section{Tide Gauge Records}

The Spanish Port Authority (Puertos del Estado, http://www.puertos.es) installed the tide gauge station of Ibiza harbor in January 2003. The station is part of the REDMAR network, at this moment comprising 21 stations distributed along the whole Spanish coast. The tide gauge deployed in Ibiza is also part of the European Sea-Level Service (ESEAS) network. The tide gauge station of Ibiza harbor (longitude $=1.44896^{\circ} \mathrm{E}$ and latitude $=38.91125^{\circ} \mathrm{N}$ ) is a radar sensor installed by the Spanish Port Authority in September 24 2009, providing sea level measurements at a $1 \mathrm{~min}$. time sampling. It was leveled during the IBIZA 2013 campaign. The leveling of the tide gauge consists in determining precisely the orthometric height $\left(N_{O}\right)$ of the gauge zero as:

$$
N_{0}=H_{0}-N
$$

where $H_{O}$ is the ellipsoidal height of the gauge zero and $N$ the undulation of the geoid at the location of the gauge.

The ellipsoidal height of the gauge zero was estimated using GNSS observations made on 14 September 2013 during 4 hours and converted into orthometric height using the mean value of the sea level in Ibiza or nivel medio del mar en Ibiza (NMMI). $H_{O}$ was found to be $0.324 \mathrm{~m}$ below the NMMI. NMMI value $(N)$ is $49.166 \mathrm{~m}$ with reference to WGS84 ellipsoid (REDMAR 2013). The absolute sea level at the tide gauge $\left(\mathrm{SSH}_{\text {tide gauge }}\right)$ is finally given by:

$$
\operatorname{SSH}_{\text {tide gauge }}(t)=h_{\text {tide gauge }}(t)+N_{0}
$$

where $h_{\text {tide gauge }}$ is the stage value in the gauge record at time $t$.

\section{Method}

\section{Ibiza Calibration Site and Experimental Design}

The Spanish/French Jason-2 and SARAL calibration campaign IBIZA 2013 was carried out on 14-16 September 2013 in the area of Ibiza Island in the NW Mediterranean Sea (Figure 1). The experiment was composed of two phases: i) the pre-calibration of the 5 buoys by reference with the Ibiza tide gauge (Figure 2a) to level the GNSS antennas above the sea level, and ii) the absolute calibration of the altimeters at the cross-over point.

The absolute calibration took place on 15 and 16 September 2013 at around 7:38 UTC under the Jason-2 ascending track 187 and around 5:29 UTC under SARAL ascending track 315 . The Spanish Navy supported the altimetry satellites calibration survey assigning the Patrol ship Toralla to the campaign (Figure 2b). She is a $133 \mathrm{Tn}$. ship, $28 \mathrm{~m}$ in length and $6.5 \mathrm{~ms}$ beam, and suitable for this kind of mission. The GNSS buoys were carried on the patrol boat deck to the calibration area. The crew placed the buoys on the sea, at the estimated observing points around the calculated satellite track two hours before the expected time of overflight. The boat kept sailing out of the survey area about 


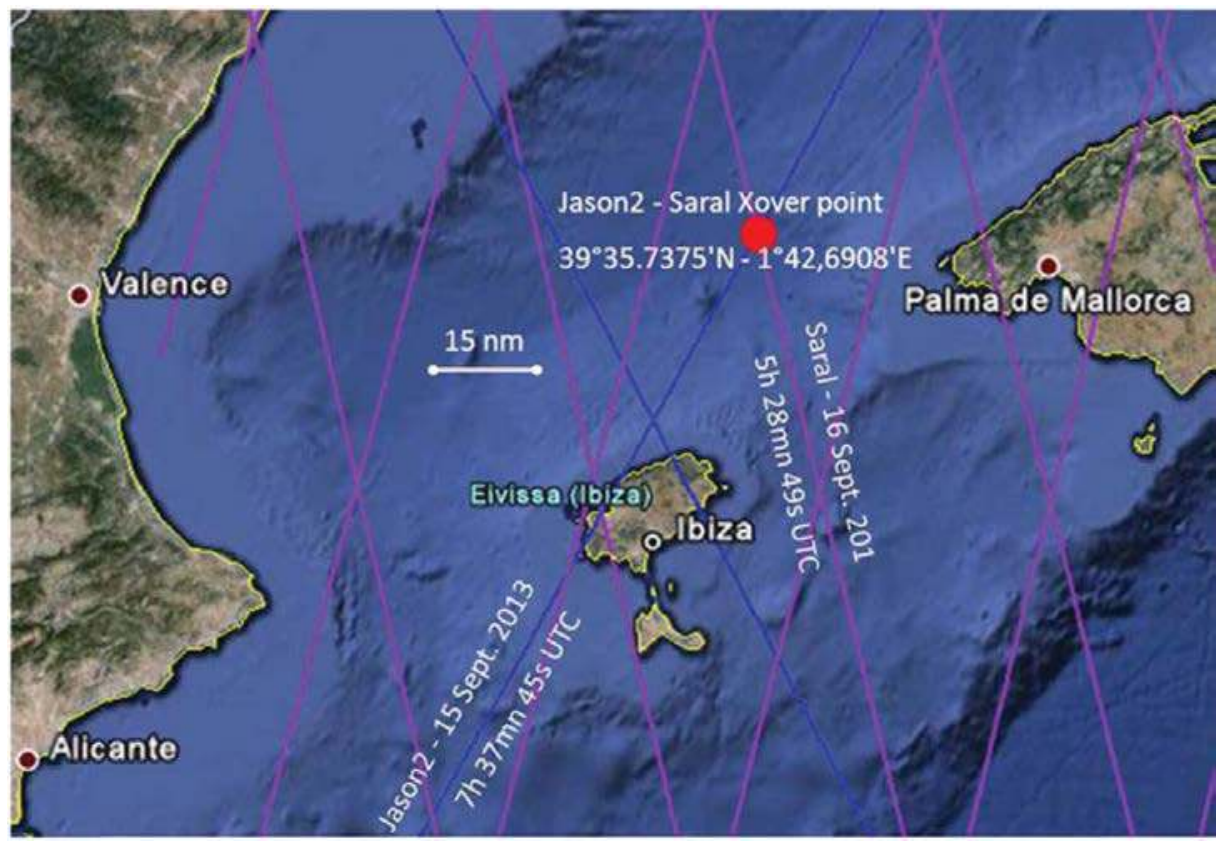

Figure 1. The geographical configuration of IBIZA 2013 absolute calibration campaign. Jason-2 tracks are represented with blue lines and Saral ones with purple lines. The white circle with a black dot represents the location of the Ibiza tide gauge used for calibration of the GNSS buoys the 14 September 2013 and the red one the crossover of Jason-2 track 196 (15 September 2013) with Saral track 274 (16 September 2013) at $40 \mathrm{~km}$ northwest of the Ibiza Island.

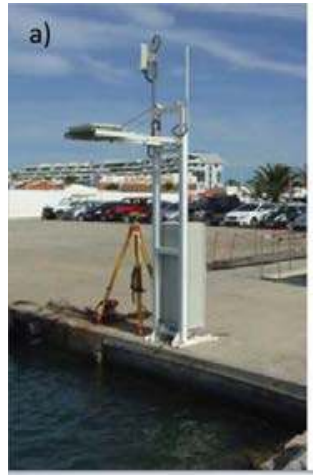

b)

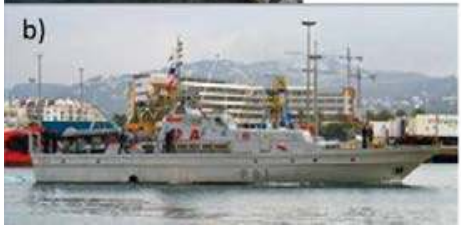

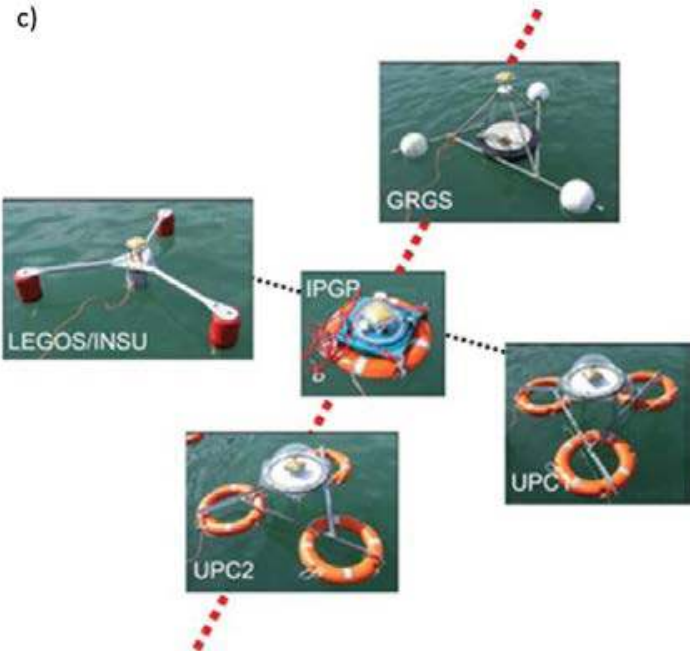

Figure 2. (a) Ibiza tide gauge (Puertos del Estado) with the GNSS used for levelling, (b) the Patrol ship Toralla from Spanish Navy (Armada Española) during the IBIZA 2013 campaign, (c) the instrumental configuration of IBIZA 2013 absolute calibration campaign. The dotted red and black lines represent the along and cross-track directions of the altimeter passes, respectively, along with the location of the buoys. 
4 hours, and then she proceeded to remove the buoys from the water. The same operation achieved for the calibration of Jason-2 was repeated the day after for SARAL. The buoys were hence deployed at least 4 hours on site to allow a precise determination of their position using GNSS Precise Point Positioning (PPP) technique. The locations of buoys deployment were estimated from Jason-2 and SARAL orbit predictions obtained from the GINS/GRGS software fitting SLR data from previous days and current and wind predictions from Mercator and Météo-France to predict the drift of the buoys between their deployment and the overflight of the satellite.

\section{Absolute Calibration Technique}

An absolute calibration of both Jason-2 and SARAL was achieved. It consists of the determination of the absolute altimeter bias that requires simultaneous measurements of $\mathrm{SSH}$ in situ and by an altimeter in the same terrestrial reference frame at the exact same location or comparison point. The absolute altimeter bias $\left(\right.$ Bias $\left._{\text {altimeter }}\right)$ is estimated as follows (Ménard et al. 1994):

$$
\text { Bias }_{\text {altimeter }}=S S H_{\text {altimeter }}-S S H_{\text {in situ }}
$$

where $\mathrm{SSH}_{\text {altimeter }}$ and $\mathrm{SSH}_{\text {in situ }}$ are the $\mathrm{SSH}$ estimated from altimeter and in situ measurements, respectively, with $S S H$ from altimeter given by Chelton et al. (2001):

$$
S S H_{\text {altimeter }}=h-\left(R+\sum \Delta R_{\text {propogation }}\right)
$$

where $h$ is the height of the centre of mass of the satellite above the ellipsoid estimated using precise orbit determination (POD) technique, $R$ is the nadir altimeter range from the center of mass of the satellite to the sea surface taking into account instrumental corrections, $\sum \Delta R_{\text {propogation }}$ is the sum of the geophysical correction to apply to the range, respectively.

$$
\sum \Delta R_{\text {propogation }}=\Delta R_{\text {ion }}+\Delta R_{d r y}+\Delta R_{\text {wet }}+\Delta R_{S S B}
$$

Where $\Delta R_{i o n}$ is the atmospheric refraction range delay due to the free electron content associated with the dielectric properties of the ionosphere, $\Delta R_{d r y}$ is the atmospheric refraction range delay due to the dry gas component of the troposphere, $\Delta R_{w e t}$ is the atmospheric refraction range delay due to the water vapor and the cloud liquid water content of the troposphere, and $\Delta R_{s s b}$ is the range correction due to the interaction of the electromagnetic pulse emitted by the altimeter with the scatterometers within the footprint. It is known as sea state bias (SSB) and is the sum of the electromagnetic $(E M)$, skewness, and tracker biases.

Altimetry data processing to obtain the SSH and selection at the cross-over were performed using the Multimission Altimetry Processing Software (MAPS, Frappart et al. 2015). A negative bias indicates that the measure of the $S S H$ by the altimeter is too low, either the altimeter range being too long, or the orbit is biased downwards (Bonnefond et al. 2013).

The $S S H$ was observed at the comparison point using five GNSS buoys located along and cross track (Figure 2c). The GNSS-derived SSH were either distance-weighting interpolated at the exact location of the of the satellite groundtrack on the sea surface at the 
exact time $t$ of the satellite overflight of the buoys or directly compared if one or several buoys are in the groundtrack of the satellite at the exact time $t$ of the satellite overflight.

\section{Calibration of the GNSS Buoys}

The calibration is an essential phase that allows to estimate the antenna height over the sea surface and determine the systematic errors and accuracy of the GNSS-derived SSH measurements (Bonnefond et al. 2003; Martinez Benjamin et al. 2004). It consists in putting into the water the buoys equipped with GNSS receiver and antenna in a close vicinity of the tide gauge for several hours. Antenna heights $\left(h_{\text {antenna }}\right)$ are determined as follows:

$$
h_{\text {antenna }}=h_{G N S S}(t)_{\mathrm{T}_{0}=1 m n}-\operatorname{SSH}_{\text {tide gauge }}(T)_{T_{1}=4 \text { hours }}
$$

where $h_{G N S S}=S S H_{\text {in situ }}+h_{\text {antenna }}$ is the elevation estimated from GNSS measurements at time $t, T_{O}$ is the sampling time of the tide gauge, $S S H_{\text {tide gauge }}$ is the absolute sea level at the tide gauge, and $T_{1}$ is the observation period close to the tide gauge.

\section{Processing of the GNSS Measurements}

As the cross-over point is located more than $50 \mathrm{~km}$ from the closest permanent GNSS station on the coast, PPP technique was chosen rather than classical differential GNSS (DGNSS) method to obtain positions with a centimeter-level accuracy. This alternative technique is powerful in such context because it does not require reference stations. Fund et al. (2013) has already demonstrate the potentiality of PPP for processing GNSS observations of sea level from buoys Nevertheless, precise GNSS satellite orbit and clock solutions given in a well-defined reference frame are needed. We used precise products from the International GNSS Service (Dow et al. 2009) and from JPL/NASA. However, compared with the DGNSS technique, PPP requires longer convergence times (typically 2 hours) estimating additional parameters (troposphere and clocks offsets), using dualfrequency receivers, and more refined observation (e.g., antenna phase center offsets and variations, phase wind-up) and earth deformation (e.g., solid earth tide, ocean loading) models (Laurichesse et al. 2008, 2009). The attitude angle of the buoy is not taken into account in the phase windup model. This error affects all observations, so it only impacts receiver clock estimates but not position solutions. Besides, the accurate solution is mainly based on carrier phase data (in order to avoid any doubt, or deeper discussions, regarding the pseudoranges which are not affected by the missing wind-up term).

The GNSS data from the pre- (14 September 2013) and post-calibration (16 September 2013) and from the absolute calibrations of Jason-2 (15 September 2013) and SARAL (16 September 2013) were processed using:

- the Géodésie par Intégrations Numériques Simultanées (GINS) software from the French Space Agency (Centre National d'Etudes Spatiales-CNES), available upon request from http://grgs.obs-mip.fr/en/research/software;

- the GPS Inferred Positioning System and Orbit Analysis Simulation Software (GIPSY-OASIS) from Jet Propulsion Laboratory (JPL), available upon request from https://gipsy-oasis.jpl.nasa.gov; and

- the Canadian Spatial Reference System-Precise Point Positioning (CSRS-PPP, http://webapp.geod.nrcan.gc.ca/geod/tools-outils/ppp.php) which is an online 


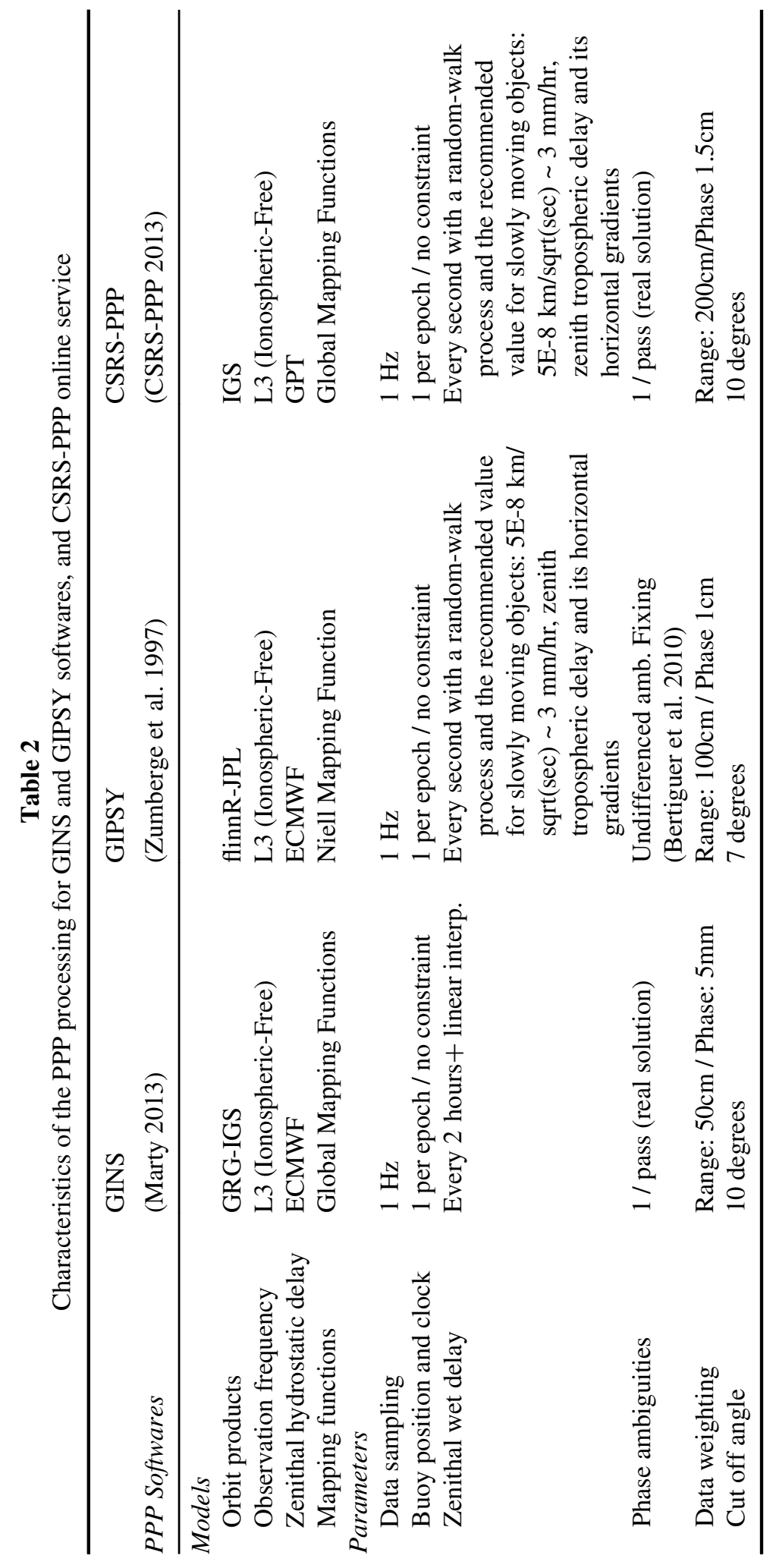


application from the Natural Resources Canada's (NRC) Geodetic Survey Division (GSD) that allows the computation of higher accuracy positions of raw GNSS data in Rinex format.

The main characteristics of the PPP processing, which allows a centimeter error level GNSS zero-differenced positioning, are summarized in Table 2.

\section{Post-processing of GNSS Measurements}

The GNSS measurements from the five buoys are first smoothed using a 5 min. averaging window and then interpolated at the exact location and time of the altimeter pass, taking into account the elevation of the antenna for each buoy obtained during the pre-calibration phase achieved in the Ibiza harbor. The corresponding sea level is then compared to the altimetry measurement to determine the absolute bias for each the altimeter following (e.g., Ménard et al. 1994; Martinez Benjamin et al. 2004; Bonnefond et al. 2013; Cancet et al. 2013).

\section{Results}

\section{Determination of Antenna Height Above Sea Level}

The buoys equipped with GNSS receiver and antenna were put into the water in a close vicinity of the Ibiza tide gauge for several hours on 14 September 2013 from $9 \mathrm{~h} 45$ to $13 \mathrm{~h} 45$ UTC for three of them (GRS, LEGOS/INSU, and IPGP) and on 16 September 2013 from 14h to $18 \mathrm{~h}$ UTC for the remaining two (UPC1 and UPC2). Precise positions of the centre of phase of the antenna with a temporal resolution of 1 second were obtained computing kinematic double-difference solutions of the GNSS buoys with a static GNSS receiver TOPCON GB-1000 with a TOPCON PG_A1+GP antenna located a few meters away from the buoys in the Ibiza harbor (Figure 2a). They were averaged on a 1-minute window for comparison with the records from the Ibiza tide-gauge. The antenna height for each buoy were estimated as the mean difference between the altitude of the center of phase of the antenna and the sea level measured by the tide gauge over the common observation period. We finally obtained the following antenna height above sea level for each buoy: $(0.765 \pm 0.007) \mathrm{m},(0.349 \pm 0.005) \mathrm{m},(0.163 \pm 0.013) \mathrm{m},(0.409 \pm 0.004)$ $\mathrm{m},(0.402 \pm 0.003) \mathrm{m}$ for GRGS, LEGOS, IPGP, UPC1, and UPC2, respectively.
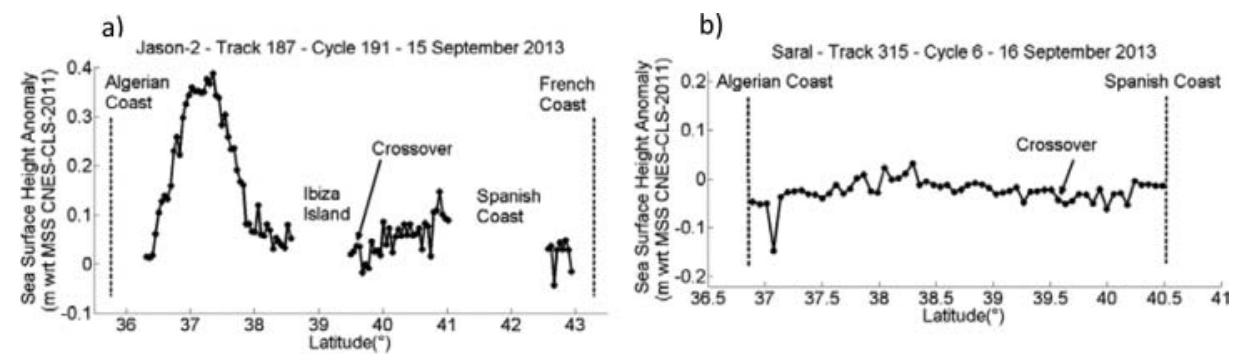

Figure 3. Differences between the altimetry-derived SSH and the MSS (CNES-CLS-2011) along Jason-2 track 187 (cycle 191-15 September 2013) (a) and SARAL track 315 (cycle 6-16 September 2013) (b). 

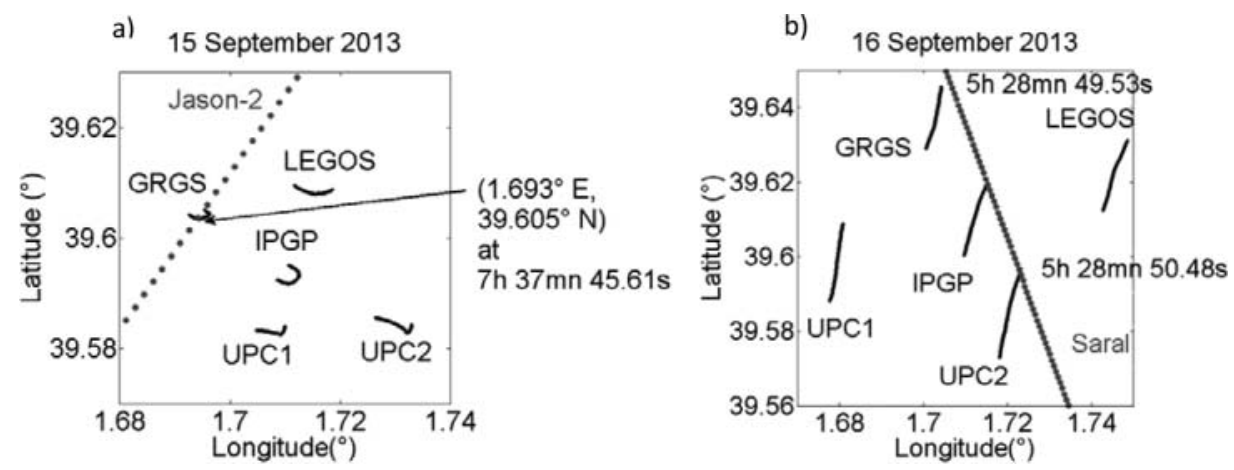

Figure 4. Location of the altimeters track (each grey point corresponding to a SSH measurement) and of the buoy drifts on 15 September 2013 along Jason-2 track 187 (a) and on 16 September 2013 along SARAL track 315 (b).

Uncertainties on antenna height are generally lower than $0.7 \mathrm{~cm}$. Larger uncertainty is found for IPGP buoy with a standard deviation (std) of $1.3 \mathrm{~cm}$. This is consistent with the larger sensitivity of this buoy to sea state (i.e., swell and waves).

\section{Validation of Altimeter-based SSH}

The along-track altimetry-derived SSH were compared to the mean sea surface (MSS) over the whole portion of the Mediterranean Sea overflown by each altimeter. Here we used the CNES-CLS-2011 MSS. Results are presented for both altimeters in Figure 3.

The differences are generally lower than 0.1 to $0.2 \mathrm{~m}$ (especially for SARAL), except close to the Algerian coast for Jason-2 where it reaches $0.4 \mathrm{~m}$, likely due to a typical intense anticyclonic gyre in the area of the Algerian Basin. They remain lower than $0.5 \mathrm{~m}$ as expected for the Mediterranean Sea (see, e.g., Cancet et al. 2013) and are less than $0.1 \mathrm{~m}$ around the crossover point. SSH from both altimeters do not present any obvious outlier in the vicinity of the crossover point.

\section{Altimeter Calibration}

Jason-2 overflew the GRGS buoy on 15 September 2013 at $7 \mathrm{~h} 37 \mathrm{mn}$ and $45.61 \mathrm{~s}$ UTC at $1.639^{\circ} \mathrm{E}$ and $39.605^{\circ} \mathrm{N}$ (Figure 4a) whereas SARAL overflew the crossover zone on 16 September 2013 at $5 \mathrm{~h} 28 \mathrm{mn}$ between 49.53 and $50.48 \mathrm{~s}$ UTC at from $1.7261^{\circ} \mathrm{E}$ and

Table 3

Absolute bias estimates for Jason-2 and SARAL using PPP technique with GINS, GIPSY and CSRS-PPP

\begin{tabular}{lcll}
\hline & \multicolumn{3}{c}{ Absolute bias $=\mathrm{SSH}_{\text {altimeter }}-\mathrm{SSH}_{\mathrm{GNSS}}(\mathrm{m})$} \\
\cline { 2 - 4 } Altimeter (Retracking) & GINS & GIPSY-OASIS & CSRS-PPP \\
\hline Jason-2 (MLE4) & 0.008 & -0.009 & -0.002 \\
Jason-2 (MLE3) & -0.008 & -0.025 & -0.018 \\
SARAL (MLE4) & $(-0.018 \pm 0.023)$ & $(-0.047 \pm 0.025)$ & $(-0.029 \pm 0.022)$ \\
\hline
\end{tabular}




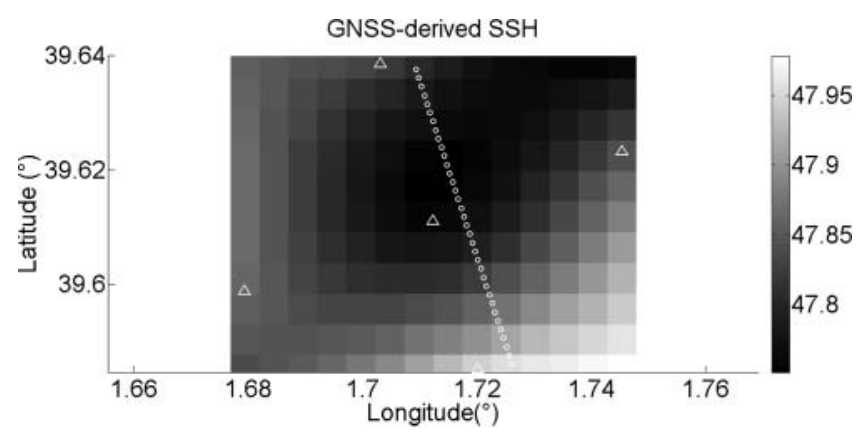

Figure 5. $S S H(\mathrm{~m})$ derived from the measurements of the GNSS buoys (white triangles). The SARAL altimetery measurements are represented by white dots.

$39.5860^{\circ} \mathrm{N}$ to $1.7093^{\circ} \mathrm{E}$ and $39.6376^{\circ} \mathrm{N}$ (Figure 4b). The trajectories of the buoys differ significantly from one day to the other due to changes in the directions of both the oceanic currents and the winds. The $S S H$ from Jason-2 was directly compared to the smoothed value, using a 5-minute moving average, of $S S H$ from the GRGS buoy. The $S S H$ from SARAL was compared along the transect to the smoothed using a 5-minute moving average window $S S H$ interpolated from GRGS, LEGOS IPGP, UPC1, and UPC2 data. The results are presented in Table 3.

The bias on the $S S H$ for Jason-2 for one comparison point vary from -0.9 to $0.8 \mathrm{~cm}$ for altimeter ranges processed using the MLE4 retracker and from -1.8 to $-0.8 \mathrm{~cm}$ with MLE3, depending on the type of GNSS processing (Table 4). GINS, GIPSY-OASIS, and CSRS-PPP processings provide similar estimates. These results are in good agreement with Jason-2 absolute bias value of from OSTST (2013).

For SARAL, SSH presents a standard deviation (std) of $3.6 \mathrm{~cm}$ over an along-track distance of $5.7 \mathrm{~km}$. The GNSS-based $S S H$ was interpolated under the altimeter track using GRGS, LEGOS, IPGP, UPC1 and UPC2 GNSS buoy measurements at the exact time of the overflight (Figure 5). The absolute bias of SARAL was estimated along the transect using 35 altimeter measurements. Very consistent values of biases were obtained using different PPP processing. Values of $(-1.8 \pm 2.3),(-4.7 \pm 2.5)$, and $(-2.9 \pm 2.2)$ $\mathrm{cm}$ along the transect were obtained using GINS, GIPSY-OASIS, and CSRS-PPP, respectively.

\section{Conclusion}

The 2013 Ibiza calibration campaign allowed to estimate the absolute biases of the AltiKa sensor onboard SARAL, that is, the first altimeter to function in Ka band, and Jason-2 at a crossover point during two consecutive days over the open ocean. The major originalities of this campaign are the use of several GNSS buoys to eventually estimate the bias in different locations along the track during the altimetry overflight, the use of the $P P P$ technique for processing the GNSS measurements, and to compare the results obtained with three different software programs. Similar bias estimates were obtained using the three $P P P$ GNSS processing software for both altimeters: $(-0.1 \pm 0.9)$ and $(-3.1 \pm 1.5) \mathrm{cm}$ for Jason-2 and SARAL, respectively. The first one is in good agreement with the Jason-2 bias value from OSTST (2013). Since Jason-2 reprocessing (GDR-D products) instrumental errors discovered by the project ( $\sim 15.6 \mathrm{~cm}$ on the range, see Bonnefond et al. 2012 for details) have been applied leading to remove the SSH bias that is now close to 0 as 
assessed by OSTST (2013). Concerning the SARAL/AltiKa SSH bias, the origin is not currently known but other studies found similar values $(-5 \mathrm{~cm})$ either from in situ (Babu et al. 2015; Bonnefond et al. 2015; Mertikas et al. 2015) or global comparisons with Jason-2 (Prandi et al. 2015; Desai and Haines 2015).

\section{Acknowledgements}

We acknowledge the Spanish Navy (Armada Española) for its support and particularly T. N. Paredes, Commanding Officer of the Toralla patrol ship, and his crew, for the excellent job made during the survey. We thank the Real Instituto y Observatorio de la Armada (ROA) for its support. We also thank the CTOH/LEGOS-OMP, France, for providing the altimetry dataset used in this study.

\section{Funding}

This study was funded under the Spanish National R+D+i program (ref: CGL200913435/CLI). This study takes part of the OSTST (CNES-NASA-NOAA-EUMETSAT) project "From Ocean to inland waters Altimetry Monitoring" (FOAM, PI P. Bonnefond).

\section{References}

Amarouche, L., P. Thibaut, O. Zanife, J.-P. Dumont, P. Vincent, and N. Steunou. 2004. Improving the Jason-1 ground retracking to better account for attitude effects. Marine Geodesy 27 (1-2):171-197.

Babu, K. N., A. K. Shukla, A. B. Suchandra, S. V. V. Arun, P. Bonnefond, L. Testut, and P. Mehra. 2015. Absolute calibration of SARAL-AltiKa in Kavaratti during its initial calibration-validation phase. Marine Geodesy 38(S1): this issue.

Bertiger, W., S. D. Desai, B. Haines, N. Harvey, A. W. Moore, S. Owen, \& J. P. Weiss. 2010. Single receiver phase ambiguity resolution with GPS data. Journal of Geodesy 84(5):327-337.

Bonnefond, P., P. Exertier, O. Laurain, O., Y. Menard, A. Orsoni, E. Jeansou, B. J. Haines, D. G. Kubitschek, and G. Born. 2003. Leveling sea surface using a GPS-catamaran. Marine Geodesy 26(3-4):319-334.

Bonnefond, P., J.-D. Desjonqueres, B. Haines, S. Mertikas, and C. Watson. 2012. Absolute calibration of the TOPEX/POSEIDON and Jason measurement systems: Twenty years of monitoring from dedicated sites. 20 Years of Progress in Radar Altimetry Symposium Proceedings, ESA SP-710, Venice.

Bonnefond, P., P. Exertier, O. Laurain, P. Thibaut, and F. Mercier. 2013. GPS-based sea level measurements to help the characterization of land contamination in coastal areas. Advances in Space Research 51(8):1383-1399.

Bonnefond, P., O. Laurain, P. Exertier, A. Guillot, N. Picot, M. Cancet, and F. Lyard. 2015. SARAL/AltiKa absolute calibration from the multi-mission Corsica facilities. Marine Geodesy 38(S1): this issue.

Born, G. H., M. E. Parke, P. Axelrad, K. L. Gold, J. Johnson, K. W. Key, D. G. Kubitschek, and E. J. Christensen. 1994. Calibration of the TOPEX altimeter using a GPS buoy. Journal of Geophysical Research 99(C12):24517-24526,

Brown, G. 1977. The average impulse response of a rough surface and its applications. IEEE Transactions on Antennas and Propagation 25(1):67-74.

Cancet, M., S. Bijac, J. Chimot, P. Bonnefond, E. Jeansou, O. Laurain, F. Lyard, E. Bronner, and P. Féménias. 2013. Regional in situ validation of satellite altimeters: Calibration and cross-calibration results at the Corsican sites. Advances in Space Research 51(8):1400-1417. 
Chelton, D. B., J. C. Ries, B. J. Haines, L. -L. Fu, and P. S. Callahan. 2001. Satellite altimetry. In Satellite Altimetry and the Earth Sciences: A Handbook of Techniques and Applications. Fu, L. -L. and A. Cazenave (eds.), San Diego: Academic Press, 1-131.

CSRS-PPP 2013. Canadian spatial reference system (CSRS) precise point positioning (PPP) service. Available at http://www.geod.nrcan.gc.ca/products-produits/ppp_e.php. Last accessed 1 July 2014.

Desai, S. and B. Haines. 2015. Cross calibration of the SARAL and OSTM near real time sea surface height measurements. Marine Geodesy: Accepted manuscript.

Dow, J. M., R. E. Neilan, and C. Rizos. 2009. The international GNSS service in a changing landscape of global navigation satellite systems. Journal of Geodesy 83:191-198.

Frappart, F., F. Papa, V. Marieu, Y. Malbéteau, F. Jordy, S. Calmant, F. Durand, S. Bala. 2015. Preliminary assessment of SARAL/AltiKa observations over the Ganges-Brahmaputra and Irrawaddy Rivers. Marine Geodesy 38(S1): this issue.

Fund, F., F. Perosanz, L. Testut, and S. Loyer. 2013. An integer precise point positioning technique for sea surface observations using a GPS buoy. Advances in Space Research 51(8): 1311-1322.

Haines, B. J., S. D. Desai, and G. H. Börn. 2010. The Harvest experiment of the climate data record from TOPEX/Poseidon, Jason-1 and the ocean surface topography mission. Marine Geodesy 33(S1):91-113.

Laurichesse, D., F. Mercier, J. P. Berthias, and J. Bijac. 2008. Real time zero-difference ambiguities blocking and absolute RTK. ION NTM 2008, San Diego.

Laurichesse, D., F. Mercier, J. -P. Berthias, J. -P., P. Broca, and L. Cerri. 2009. Integer ambiguity resolution on undifferenced GPS phase measurements and its application to PPP and satellite precise orbit determination. Navigation, Journal of the Institute of Navigation 56(2):135-149.

Loyer, S., F. Perosanz, F. Mercier, H. Capdeville, and J. -C. Marty. 2012. Zero-difference GPS ambiguity resolution at CNES-CLS IGS Analysis Center. Journal of Geodesy 86(11): 991-1003.

Martinez-Benjamin, J. J., M. Martinez-Garcia, S. Gonzalez Lopez, A. Nuñez Andres, F. Buill Pozuelo, M. Espino Infantes, J. Lopez-Marco, J. Martin Davila, J. Garate Pasquin, C. Garcia Silva, P. Bonnefond, O. Laurain, M. Baron Isanta, M.A. Ortiz Castellon, J. Talaya Lopez, B. Perez Gomez, E. Alvarez Fanjul, G. Rodriguez Velasco, D. Gomis, M. Marcos, Y. Menard, G. Jan, E. Jeansou, F. Lyard, and L. Roblou. 2004. Ibiza absolute calibration experiment: Survey and preliminary results. Marine Geodesy 27(3-4):657-681.

Marty, J. C. (eds.). 2013. Algorithmic documentation of the Gins software. Available at grgs.obsmip.fr/content/download/1460/9226/file/GINS_Algo_2013.pdf. Last accessed 1 July 2014.

Ménard, Y., E. Jeansou, and P. Vincent. 1994. Calibration of the TOPEX/Poseidon altimeters at Lampedusa: Additional results at Harvest. Journal of Geophysical Research 99(C12):2448724504.

Mertikas, S. P., R. T. Ioannides, I. N. Tziavos, G. S. Vergos, W. Hausleitner, X. Frantzis, A. Tripolitsiotis, P. Partsinevelos, and D. Andrikopoulos. 2010. Statistical models and latest results in the determination of the absolute bias for the radar altimeters of Jason satellites using the Gavdos facility. Marine Geodesy 33(1):114-149.

Mertikas, S. P., A. Daskalakis, I. N. Tziavos, G. Vergos, and V. Zervakis. 2015. First calibration results for the SARAL/AltiKa altimetric mission using the Gavdos permanent facilities. Marine Geodesy 38(S1): this issue.

OSTST. 2013. Report of the ocean surface topography science team meeting. Willis, J. and P. Bonnefond (eds.). Available at http://www.aviso.altimetry.fr/fileadmin/documents/OSTST/2013/ oral/OSTST_2013_Meeting_Report.pdf. Last accessed 1 July 2014.

Prandi, P., S. Philipps, V. Pignot, and N. Picot. 2015. SARAL/AltiKa global statistical assessment and cross-calibration with Jason-2. Marine Geodesy 38(S1): this issue.

REDMAR. 2013. Red de maréografos de Puertos del Estado (Informe anual 2013), Area de Medio Físico. Madrid: Puertos del Estado. 
Rocken, C., T. M. Kelecy, G. H. Born, L. E. Young, G. H. Purcell, and S. K. Wolf. 1990. Measuring precise sea level from a buoy using the global positioning system. Geophysical Research Letters 1712:2145-2148.

Rodriguez, E. 1988. Altimetry for non-Gaussian oceans: Height biases and estimation of parameters. Journal of Geophysical Research 93(C11):14107-14120.

Verron, J., P. Sengenes, J. Lambin, J. Noubel, N. Steunou, A. Guillot, N. Picot, S. Coutin-Faye, R. Gairola, D. V. A. Raghava Murthy, J. Richman, D. Griffin, A. Pascual, F. Rémy, and P. K. Gupta. 2015. The SARAL/AltiKa altimetry satellite mission. Marine Geodesy 38(S1): this issue.

Watson C. S., N. C. White, J. A. Church, R. J. Burgette, P. Tregoning, and R. Coleman. 2011. Absolute calibration in Bass Strait, Australia: TOPEX, Jason-1 and OSTM/Jason-2. Marine Geodesy 34(3-4):242-260.

Zumberge, J. F., M. B. Heflin, D. C. Jefferson, M. M. Watkins, and F.H. Webb. 1997. Precise point positioning for the efficient and robust analysis of GPS data from large networks. Journal of Geophysical Research 102(B3):5005-5017. 